\title{
Questionable Ethical Clearance, Incorrect Recommendations and Indiscernible Merit
}

\author{
Ashish Chakranarayan ${ }^{1}$
}

Received: 9 October 2015 / Accepted: 23 November 2015/Published online: 2 February 2016

(C) The Association of Oral and Maxillofacial Surgeons of India 2016

\section{Dear Sir,}

1. I am writing regarding an article "ASSESSMENT OF EFFICACY OF SUBMENTAL INTUBATION IN THE MANAGEMENT OF MIDFACE AND PANFACIAL TRAUMA", published in JMOS, Jul-Sep 2015 issue, pages 674-681. Following are my observations.

(a) Majority of the cases mentioned in the results vide Table 1 (Results) are not indicated for submental intubation. In fact, it appears to be a clear case of incorrect study design/incorrect inclusion criteria/unethical study, wherein an invasive procedure was performed in majority of the cases included in this study where it was not indicated [1].

(b) The authors incorrectly recommend that "submental intubation should be chosen whenever possible in cases of PURELY maxillofacial trauma". There are specific indications for the technique and most cases would not qualify for it routinely [2]. (c) The conclusions put forth already well established facts and are completely irrelevant to the title of the publication.

2. The publication of this article raises some pertinent questions

(a) How did the ethics committee approve of an invasive procedure where it was not indicated?

(b) What was the compulsion on the reviewer to accept such an article for publication?

(c) Should the article not be retracted?

3. If you feel that the observations are valid, necessary action may be taken at your end.

\section{References}

1. Gadre KS (2010) Transmylohyoid/submental intubation: review, analysis, and refinements. J Craniofac Surg 21:516-519

2. Das S (2012) Submental intubation: a journey over the last 25 years. J Anesthesiol Clin Pharmacol 28(3):291-303

Ashish Chakranarayan

ashish_chakranarayan@hotmail.com

1 Military Dental Centre, Jabalpur, 482001 MP, India 